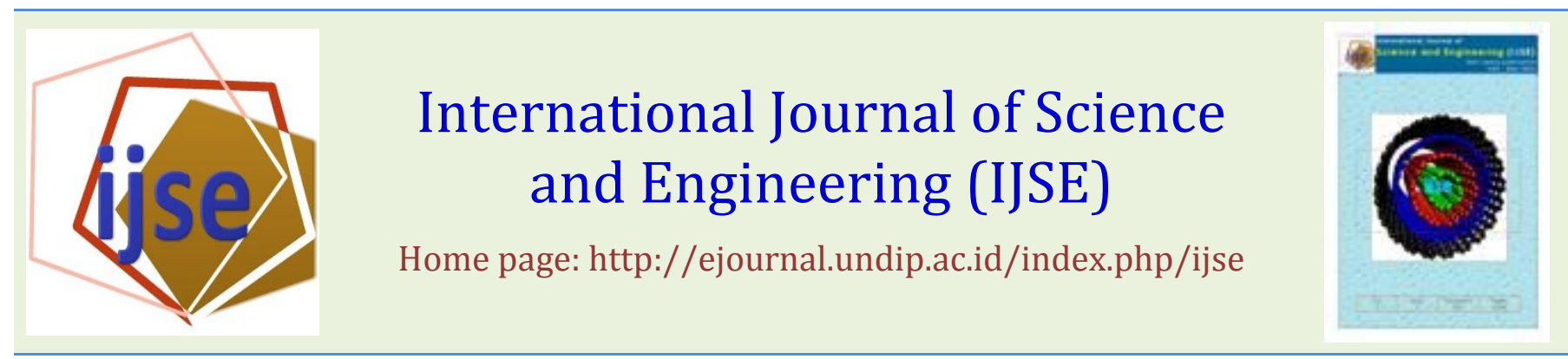

\title{
Application of Response Surface Methodology in Extraction of Bioactive Component from Palm Leaves (Elaeis guineensis)
}

\author{
Nur Afiqah Arham¹, Nurul Amal Nadhirah Mohamad ${ }^{1}$, Junaidah Jai*1, Jagannathan Krishnan ${ }^{1}$, Noorsuhana \\ Mohd Yusof ${ }^{1}$ \\ 1 Department of Chemical Engineering, Universiti Teknologi MARA, Shah Alam 40450, Malaysia \\ Corresponding Author: junejai@salam.uitm.edu.my
}

\begin{abstract}
The hydroxyl groups of the polyphenols are capable to act as reducing agent for reduction reaction. The effect of drying temperature, extraction temperature and extraction duration were evaluated using central composite design which consists of 20 experimental runs. Response surface methodology (RSM) was used to estimate the optimum parameters in extracting polyphenols from the palm leaves. The correspondence analysis of the results yielded a quadratic model which can be used to find optimum conditions of extraction process. The optimum extraction condition of drying temperature, extraction temperature and extraction duration are $70^{\circ} \mathrm{C}$, at $70^{\circ} \mathrm{C}$ of 10 minutes, respectively. Total polyphenols were determined by application of the Folin-Ciocalteu micro method and the extract was found contain of $8 \mathrm{mg}$ GAE/g dry palm leaves at optimum conditions.
\end{abstract}

Key words - Extraction, hydroxyl; palm leaves; polyphenols; response surface methodology

Submission: September 15, 2013

Corrected : October 6, 2013

Accepted: October 14, 2013

Doi: $10.12777 /$ ijse. $5.2 .95-100$

[How to cite this article: Arham, N.A., Mohamad, N.A.N., Jai, J., Krishnan, J., Noorsuhana Mohd Yusof, N.M. (2013). Application of Response Surface Methodology in Extraction of Bioactive Component from Palm Leaves (Elaeis guineensis). International Journal of Science and Engineering, 5(2),95-100. Doi: 10.12777/ijse.5.2.95-100

\section{Introduction}

Oil palm leaves are biomass produced throughout the year. They are pruned during harvesting process and left rotting for nutrient recycling. Recent studies found that palm leaves extract are rich in phenolic content and exhibit good antioxidant activity [1, 2]. Screening of palm leaves extract performed by Sasidharan et al. [3] revealed the presence of tannins, alkaloids, reducing sugars, steroids, saponins, terpenoid, and flavonoids. According to NgMei and ChooYuen [4] the phenolic contents was higher in dried palm leaves extract compared to fresh palm leaves extract.

Phenolic has at least one hydroxyl group attached to an aromatic ring. The common classes of phenolic compounds naturally found in plants are phenolic acids, flavonoids and tannins. Usually the total phenolic content (TPC) is expressed as gallic acid equivalent (GAE) per gram dry weight. The gallic acid was chosen as the standard to represent the various types of phenolic compounds mostly due to its stability, active antioxidant activity and reproducible result [5].
Traditionally, optimization was performed by considering single factor at a time. The use of response surface methodology (RSM) in the process optimization is a time and cost saving approach because the number of experimental trials required to evaluate multiple variables and their interactions is reduced [6]. Most of previous studies on optimization of phenolic content extraction employed central composite design (CCD) as their experimental design [7-9].

The objective of the present study is to optimize the processing conditions (drying temperature, extraction temperature and extraction duration) for maximum phenolic content extracted from palm leaves by applying RSM. These conditions will serves as a preliminary basis for conducting further studies on the application of palm leaves extract as the reducing agent for synthesis of metallic nanoparticles.

\section{Materials and Methods \\ Experimental Materials and Chemicals}

The palm leaves were obtained from Pasir Panjang, Sekinchan, Selangor, Malaysia. The collected leaves are the leaves that have been pruned from the tree. Folin- 
Ciocalteu, Gallic acid and Sodium Carbonate were purchased from Merck where all the reagents are of analytical grade.

\section{Preparation of plant extract}

The collected palm leaves were washed with distilled water, cut into small pieces and oven-dried. The plant samples were dried at different temperature (65$75^{\circ} \mathrm{C}$ ) and were ground into small pieces. The palm leaves extract was prepared by weighing $20 \mathrm{~g}$ of dried palm leaves in $250 \mathrm{ml}$ beaker along with $200 \mathrm{ml}$ of distilled water at varied temperature $\left(68-72^{\circ} \mathrm{C}\right)$ and time $\quad(7-13$ $\min$ ) before filtered through filter paper.

\section{Determination of total polyphenols}

The total phenolic content (TPC) was determined according the Folin-Ciocalteu micro method by Waterhouse [10]. A $0.1 \mathrm{ml}$ sample was mixed with $7.9 \mathrm{ml}$ water and $0.5 \mathrm{ml}$ Folin-Ciocalteu solution $\left(\mathrm{C}_{6} \mathrm{H}_{6} \mathrm{O}\right)$. After 5 min, $0.15 \mathrm{ml}$ of sodium carbonate $\left(\mathrm{Na}_{2} \mathrm{CO}_{3}\right)$ were added to the mixture. The mixture then was left at $40^{\circ} \mathrm{C}$ for $30 \mathrm{~min}$ before the absorbance of the mixture was measured against the blank reagent at $765 \mathrm{~nm}$ using spectrophometry. The quantification of TPC was measured using calibration curve of Gallic acid and results were expressed as mg Gallic acid equivalent (GAE)/g dry plant [11].

\section{Response surface methodology}

Respond surface method (RSM) is an experimental optimization procedure based on experiments and experimented observations [12]. The three independent variables considered were drying temperature $\left(\mathrm{x}_{1}, \mathrm{~A}\right)$, extraction temperature $\left(\mathrm{x}_{2}, \mathrm{~B}\right)$ and extraction time $\left(\mathrm{x}_{3}, \mathrm{C}\right)$ while response variable was the yield of TPC. A central composite design (CCD) was selected for the optimization of process with 20 runs, including six replicates at central point [13]. In Table 1, the range and levels of independent variables were presented in their coded forms. The quadratic equation model for predicting optimal point was expressed according to the following equation:

$y_{n}=a_{0}+\sum_{i=1}^{3} a_{i} x_{i}+\sum_{i=1}^{3} a_{i i} x_{i i}+\sum_{i=j=1}^{3} a_{i j} x_{i} x_{j}$

where $Y_{n}$ represent the response variables, $a_{0}$ is a constant, $a_{i}, a_{i i}$ and $a_{i j}$ are the linear, quadratic and interactive coefficients, respectively. $\mathrm{x}_{\mathrm{i}}$ and $\mathrm{x}_{\mathrm{j}}$ are the levels of the independent variables. Three-dimensional surface response plots were generated by varying two variables within the experimental range and holding the other constant at the central point. The experiment was designed and analyzed by Minitab 16 software (Minitab Inc., USA). The regression and estimated regression coefficients were considered to be notable when the $P$ value $<0.05$ [14]. Surface plots were performed and optimal extraction conditions were determined with Minitab 16.

Table 1. Values of the independent parameters and their coded forms with their symbols employed in RSM for optimization of palm leaves extraction process

\begin{tabular}{|c|c|c|c|}
\hline Independent parameters & Symbols of the parameters & $\begin{array}{c}\text { Original values of the } \\
\text { parameters }\end{array}$ & $\begin{array}{c}\text { Coded forms of the } \\
\text { parameters }\end{array}$ \\
\hline \multirow[t]{5}{*}{ Drying temperature $\left({ }^{\circ} \mathrm{C}\right)$} & $\mathrm{x}_{1}$ & 62.0 & $-\alpha$ \\
\hline & & 65.0 & -1 \\
\hline & & 70.0 & 0 \\
\hline & & 75.0 & 1 \\
\hline & & 78.5 & $+\alpha$ \\
\hline \multirow[t]{5}{*}{ Extraction temperature $\left({ }^{\circ} \mathrm{C}\right)$} & $\mathrm{x}_{2}$ & 66.6 & $-\alpha$ \\
\hline & & 68.0 & -1 \\
\hline & & 70.0 & 0 \\
\hline & & 72.0 & 1 \\
\hline & & 73.4 & $+\alpha$ \\
\hline \multirow[t]{5}{*}{ Extraction time (min) } & $\mathrm{x}_{3}$ & 5.0 & $-\alpha$ \\
\hline & & 7.0 & -1 \\
\hline & & 10.0 & 0 \\
\hline & & 13.0 & 1 \\
\hline & & 15.0 & $+\alpha$ \\
\hline
\end{tabular}

\section{Results and Discussion}

Effect of plant drying temperature $\left(65-75^{\circ} \mathrm{C}\right)$, extraction temperature $\left(68-72^{\circ} \mathrm{C}\right)$ and extraction time $(7-$ $13 \mathrm{~min}$ ) on total phenolic content (TPC) were investigated. The responses obtained for TPC from the 20 experiments are shown in Table 2.

The estimated main effects and interaction effects were examined from the main effects plots as shown in
Figure 1 and interaction plots (Fig. 2). The steep effect lines obtained for the main effects of drying temperature (TD) and extraction time (t) denote that they affected the phenolic content significantly (Fig. 1). From the interaction plots (Fig. 2), the unparallel effect lines for the TDTE and TEt interaction implies that there was rather strong two-way interaction between the main effects of TD-TE and also between TE-t. Meanwhile, the interactions 
between main effects TD-t was relatively weak since their effect lines are nearly parallel.

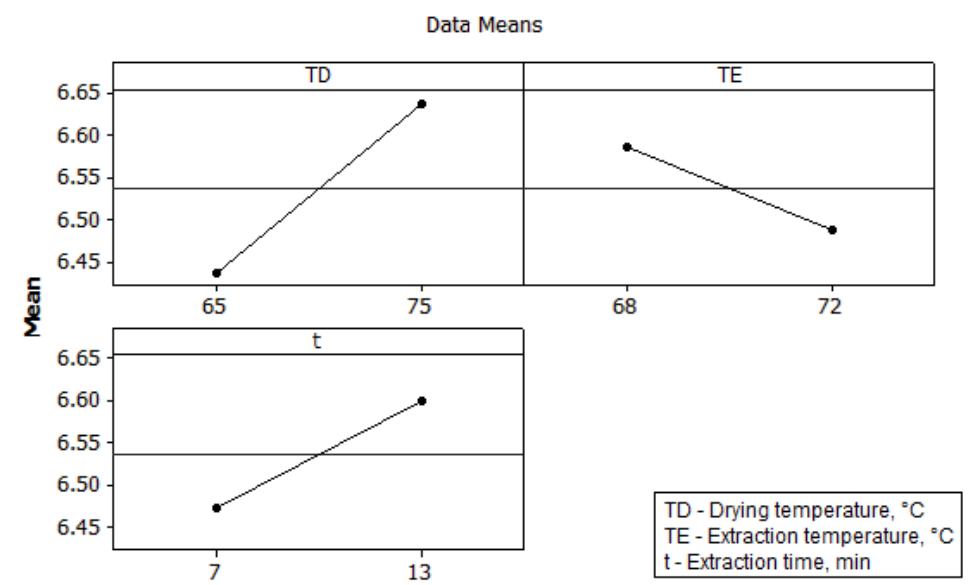

Figure 1. Main effect plots of drying temperature, extraction temperature and extraction time

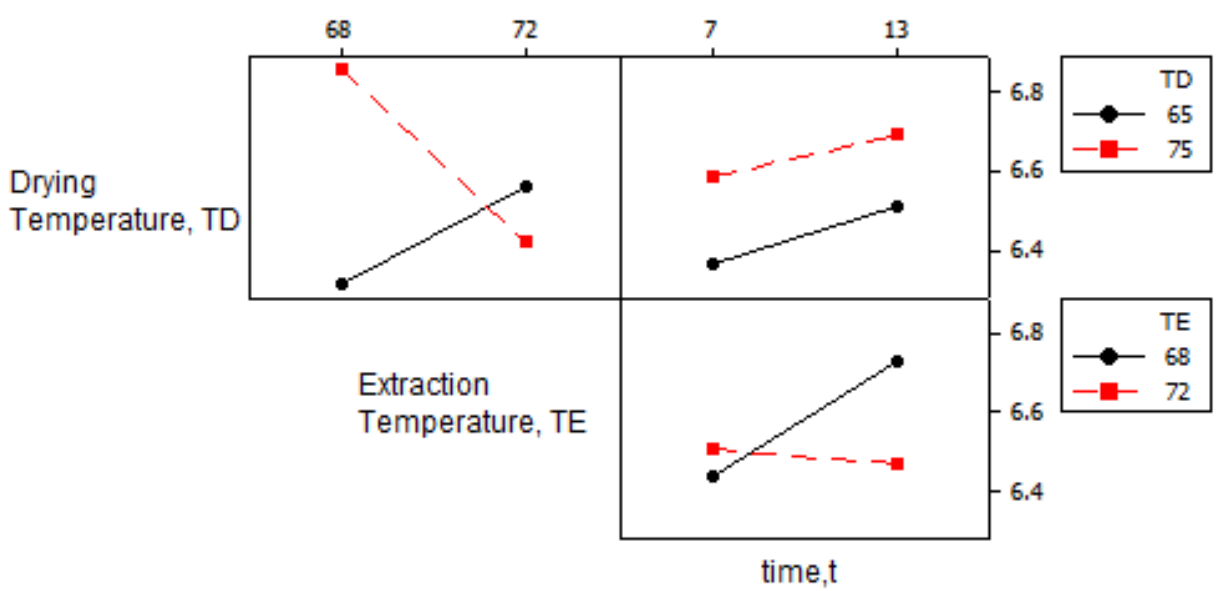

Figure 2. Interaction effect plots between drying temperature, extraction temperature and extraction time

Response surface analysis of the data in Table 2 demonstrates that the relationship between the total phenolic content and the processing conditions to extract the phenolic compounds is quadratic. Fig. 3 (A) is a response surface plot showing the effect of drying temperature and extraction temperature on the total phenolic content at the fixed extraction duration of 10 minutes. The drying temperature was shown as quadratic effect on the total phenolic content. The total phenolic content initially increased and then decreased when drying temperature increased, which revealed that moderate drying temperature was favorable for extracting phenolic compounds from palm leaves. With regard to extraction temperature, the total phenolic content shows different pattern when compared to drying temperature (Fig. 3 (A)) and extraction duration (Fig. 3 (C)). According to Prasad et al. [8] a rise in temperature can rupture the phenolic matrix bonds and influence the membrane structure of plant cells thus increasing phenolic diffusion rate. However, elevated temperature could degrade phenolic compounds.

The extraction duration also shows quadratic effect on the total phenolic content. The total phenolic content increased with increase in temperature up to a certain extent and then decreased. Prasad et al. [8] obtained highest phenolic content from Mangifera pajang when carried out extraction at $58{ }^{\circ} \mathrm{C}$ for 30 minutes. Extraction of phenolic compounds from mangosteen hull carried out by Cheok et al. [9] at room temperature required 2 hour of extraction duration to obtained highest phenolic content. Contradictory, this study achieved highest phenolic content after 10 minutes of extraction at $70^{\circ} \mathrm{C}$. Therefore, increasing in temperature has increased the extraction rate, but also reduced the extraction time. 
Table 2. Central Composite Design arrangement and responses of total phenolic content (TPC) based on drying temperature, extraction temperature and extraction time.

\begin{tabular}{ccccc}
\hline Run Order & $\begin{array}{c}\text { Drying Temperature, } \mathbf{x}_{\mathbf{1}} \\
\left({ }^{\circ} \mathbf{C}\right)\end{array}$ & $\begin{array}{c}\text { Extraction } \\
\text { Temperature, } \mathbf{x} \mathbf{2}\left({ }^{\circ} \mathbf{C}\right)\end{array}$ & $\begin{array}{c}\text { Extraction time, } \mathbf{x}_{3} \\
(\mathbf{m i n})\end{array}$ & $\begin{array}{c}\text { TPC, } \mathbf{Y} \mathbf{1} \text { (mg GAE/g dry } \\
\text { plant) }\end{array}$ \\
\hline 1 & 70.0 & 70.0 & 10 & 7.105 \\
2 & 70.0 & 66.6 & 10 & 7.044 \\
3 & 70.0 & 70.0 & 10 & 7.195 \\
4 & 78.5 & 70.0 & 10 & 7.389 \\
5 & 70.0 & 70.0 & 10 & 6.653 \\
6 & 75.0 & 72.0 & 7 & 6.671 \\
7 & 65.0 & 72.0 & 13 & 6.777 \\
8 & 65.0 & 68.0 & 13 & 6.242 \\
9 & 70.0 & 70.0 & 10 & 7.167 \\
10 & 70.0 & 70.0 & 5 & 6.702 \\
11 & 75.0 & 72.0 & 13 & 6.162 \\
12 & 75.0 & 68.0 & 13 & 7.221 \\
13 & 75.0 & 68.0 & 7 & 6.495 \\
14 & 65.0 & 72.0 & 7 & 6.341 \\
15 & 70.0 & 70.0 & 10 & 7.362 \\
16 & 65.0 & 68.0 & 7 & 6.382 \\
17 & 70.0 & 70.0 & 15 & 7.276 \\
18 & 62.0 & 70.0 & 10 & 6.618 \\
19 & 70.0 & 73.4 & 10 & 7.874 \\
20 & 70.0 & 70.0 & 10 & 8.005 \\
\hline
\end{tabular}

(A)

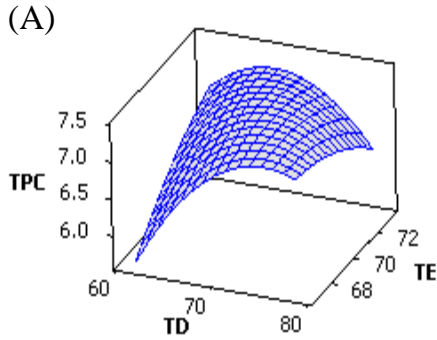

(B)

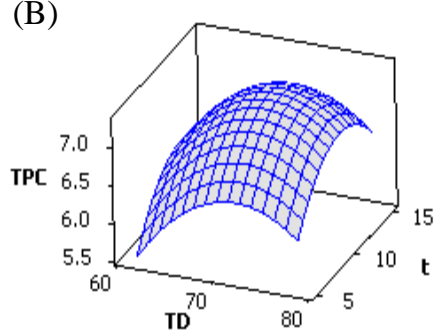

(C)

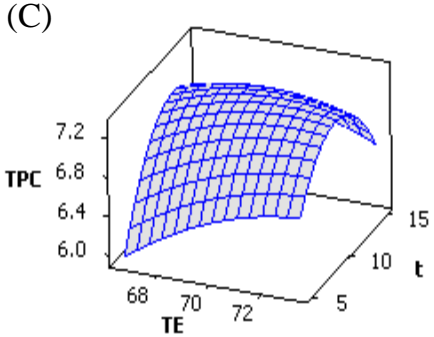

Figure 3. Surface plot of the total phenolic content (TPC) as a function of (A)drying temperature and extraction temperature at extraction duration of 10 minutes, (B) drying temperature and extraction duration at extraction temperature of $70{ }^{\circ} \mathrm{C},(\mathrm{C})$ extraction temperature and extraction duration at drying temperature of $70{ }^{\circ} \mathrm{C}$.

The capability of this extract to act as reducing agent has been experimented in synthesis of Ag nanoparticles. It was found that the particles formed were in nano-scale sized (Fig. 4). From the FTIR studied (Fig. 5), it was found that there was large $-\mathrm{OH}$ stretches obtained from the palm leaves extract $\left(3307 \mathrm{~cm}^{-1}\right)$. However, the FTIR spectra for the residue solution of Ag synthesis showed that there was no longer $-\mathrm{OH}$ stretches in the solution. This suggests that hydroxyl group was responsible as reductant in the formation of $\mathrm{Ag}$ nanoparticles 


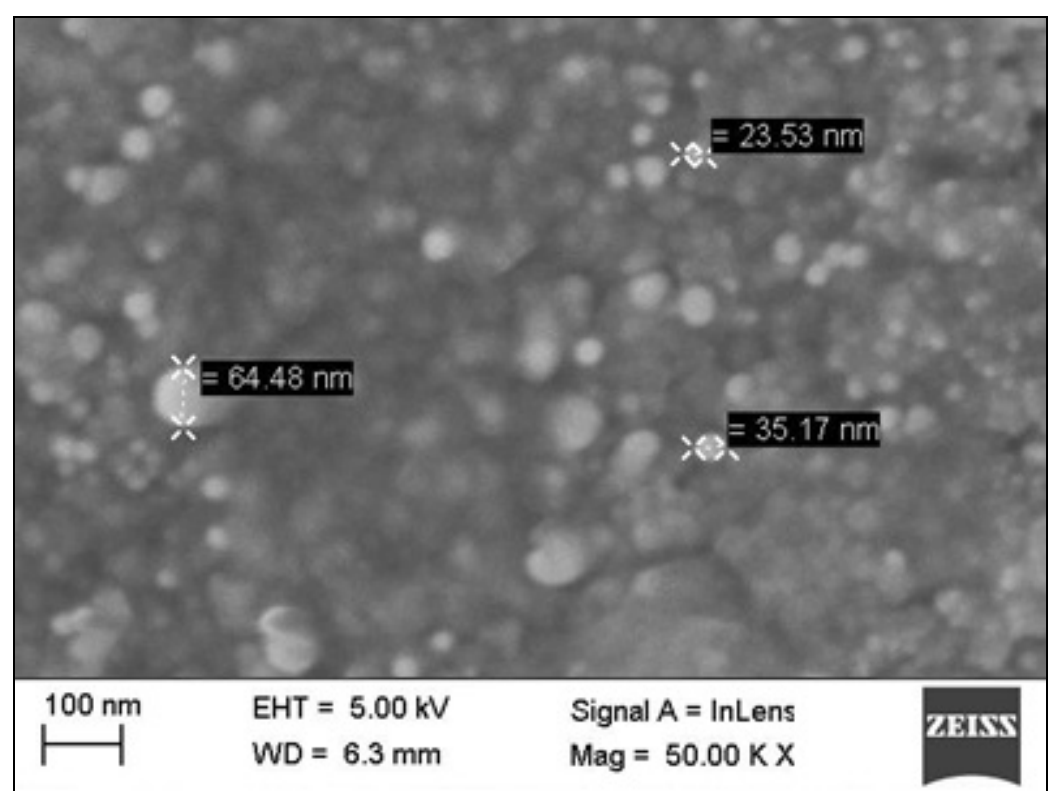

Figure 4. FESEM image of Ag nanoparticles formed from bioreduction, with $20 \mathrm{ml}$ of palm leaves extract and $80 \mathrm{ml}$ of $10 \mathrm{mM}$ aqueous solution of $\mathrm{AgNO}_{3}$

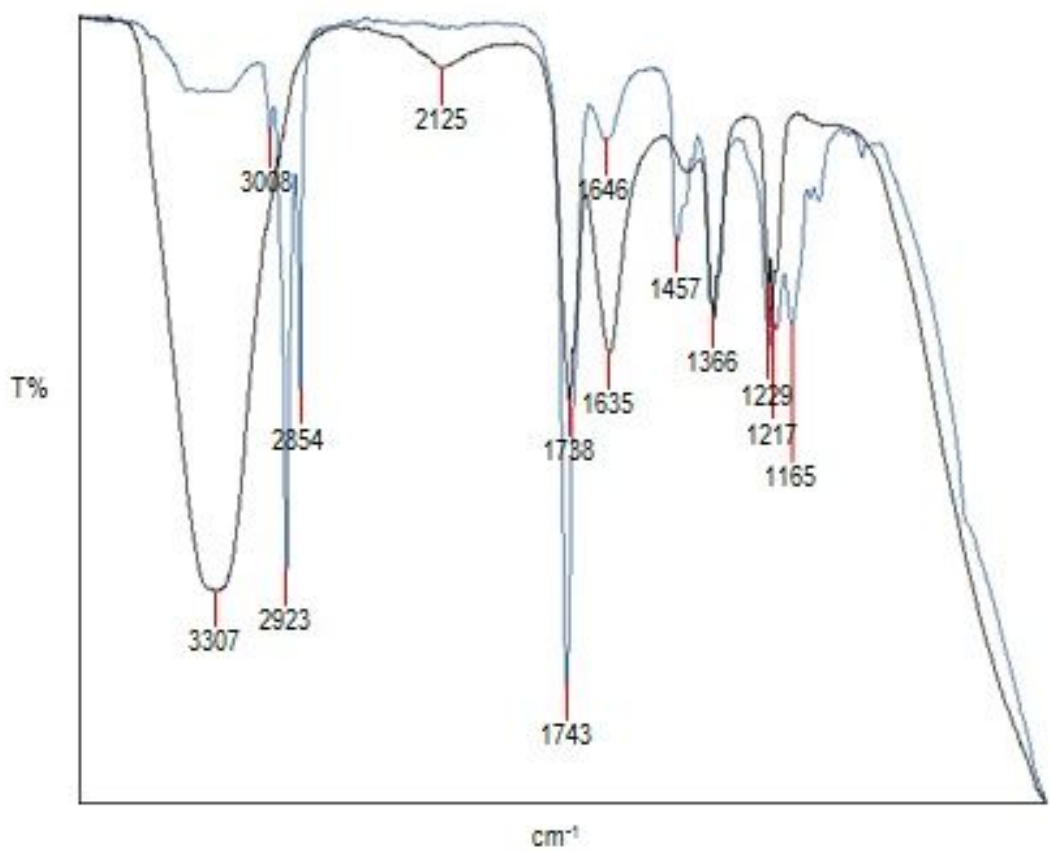

Residue solution of Ag synthesis Palm leaves extract

Figure 5. FTIR spectra of palm leaves extract and residue solution of Ag synthesis.

\section{Conclusions}

Response surface methodology was successfully implemented for optimization of total phenolic content (TPC). The maximal TPC predicted by response surface analysis was $8.005 \mathrm{mg} \mathrm{GAE} / \mathrm{g}$ of dried palm leaves under the following condition: the drying temperature of $70^{\circ} \mathrm{C}$, extraction temperature of $70{ }^{\circ} \mathrm{C}$ and extraction duration of 10 minutes. Palm leaves extracts can thus be used in synthesis of metallic nanoparticles as reducing agent since it is rich in polyphenols.

\section{Acknowledgements}

Financial support of this work by the Research Acculturation Grant Scheme (RAGS), Project No.
RAGS/2012/UITM/TK05/6, is gratefully acknowledged. We would like to thank Mr. Muhammad Zahid Yusuf, owner of oil palm estate in Sekinchan, Selangor for supplying all the oil palm leaves samples.

\section{References}

[1] R.T. Rosalina Tan, S. Mohamed, G.F. Samaneh, M.M. Noordin, Y.M. Goh, M.Y.A. Manap, International Food Research Journal 18 (2011) 179-188.

[2] V. Soundararajan, S. Sreenivasan, APCBEE Procedia 2 (2012) 153159.

[3] S. Sasidharan, R. Nilawatyi, R. Xavier, L.Y. Latha, R. Amala, Molecules 15 (2010) 3186-3199.

[4] H. NgMei, M. ChooYuen, American Journal of Applied Sciences 7 (2010) 1243-1247. 
[5] D. Sreeramulu, M. Raghunath, Food Research International 43 (2010) 1017-1020.

[6] C. Zhu, X. Liu, Carbohydrate Polymers 92 (2013) 1197-1202.

[7] B. Yang, X. Liu, Y. Gao, Innovative Food Science \& Emerging Technologies 10 (2009) 610-615.

[8] K.N. Prasad, F.A. Hassan, B. Yang, K.W. Kong, R.N. Ramanan, A. Azlan, A. Ismail, Food Chemistry 128 (2011) 1121-1127.

[9] C.Y. Cheok, N.L. Chin, Y.A. Yusof, R.A. Talib, C.L. Law, Industrial Crops and Products 40 (2012) 247-253.

[10] A. Waterhouse, no date), http://water house. ucdavis. edu/phenol/folinmicro. htm,(Accessed: May 2011) (2009).
[11] H.S. Yim, F.Y. Chye, S.M. Koo, P. Matanjun, S.E. How, C.W. Ho, Food and Bioproducts Processing 90 (2012) 235-242.

[12] H. Zhang, J.W. Wang, S.Z. Dong, F.X. Xu, S.H. Wang, Advanced Materials Research 393 (2012) 1024-1028.

[13] Y. Gong, Z. Hou, Y. Gao, Y. Xue, X. Liu, G. Liu, Food and Bioproducts Processing 90 (2012) 9-16.

[14] Y. Li, G.K. Skouroumounis, G.M. Elsey, D.K. Taylor, Food Chemistry 129 (2011) 570-576. 